\title{
Consideraciones críticas del fenómeno delirante inicial en el Método Paranoico Crítico de Salvador Dalí y el edificio CCTV de Rem Koolhaas
}

\author{
Ferran Ventura Blanch \\ Universidad de Málaga \\ ferranventura@uma.es
}

RESUMEN: El objetivo de este artículo es demostrar la vigencia del Método Paranoico crítico de Salvador Dalí en su aplicación a la interpretación y análisis del arte y la arquitectura, que el artista definió en su obra El mito trágico de «El ángelus» de Millet. Para ello se aplicará a la interpretación de la arquitectura de Rem Koolhaas, y en concreto a su edificio de la televisión China, el CCTV en Beijing. Se trabaja en convivencia con el plano imaginario y el plano más analítico siguiendo distintos caminos.

El fenómeno delirante inicial es el instante en que aparece por primera vez, de forma violenta, la imagen obsesiva, sobre la que se aplica el método paranoico crítico. Aquí el fenómeno delirante inicial es el acontecimiento del incendio del TVCC en Beijing producido en 2009. Desde que se manifiesta el mismo, la imagen real queda anclada al fenómeno delirante de forma instantánea.

PALABRAS CLAVE: Delirio; Surrealismo; Dalí; Koolhaas; Millet; Rascacielos.

\section{Critical Considerations of the Initial Delirious Phenomenon in the Critical Paranoid Method of Salvador Dalí and the CCTV Building of Rem Koolhaas}

ABSTRACT: The objective of this article is to demonstrate the validity of Salvador Dali's Critical Paranoid Method in its application to the interpretation and analysis of art and architecture, which the artist defined in his work Le mythe tragique de «L'Angélus» de Millet. For this, it will be applied to the interpretation of the architecture of Rem Koolhaas, and in particular to his Chinese television building, the CCTV in Beijing. It works in harmony with the imaginary plane and the most analytical plane following different paths.

The initial delusional phenomenon is the moment in which the obsessive image appears for the first time, on which the critical paranoid method is applied. Here the initial delusional phenomenon is the event of the TVCC fire in Beijing in 2009. Since it becomes apparent, the real image is instantly anchored to the delusional phenomenon.

KEYWORDS: Delirious; Surrealism; Dalí; Koolhaas; Millet; Skyscraper.

Recibido: 23 de febrero de 2020 / Aceptado: 6 de mayo de 2020.

Introducción

Todas las noches, los rascacielos de Nueva York toman las antropomórficas formas de múltiples y gigantescos Ángelus de Millet del período terciario, inmóviles y listos para ejecutar el acto sexual y devorarse entre sí, como enjambres de alacranes antes de la cópula. Es el ingastado deseo sanguinario lo que les alumbra y hace circular toda su central calefacción y poesía por su ferruginosa osamenta de diplodoco vegetal (Dalí, 1942: 359) [1].

Cómo citar este artículo: VENTURA BLANCH, Ferran, "Consideraciones críticas del fenómeno delirante inicial en el Método Paranoico Crítico de Salvador Dalí y el edificio CCTV de Rem Koolhaas", Boletín de Arte-UMA, n. ${ }^{\circ}$ 42, Departamento de Historia del Arte, Universidad de Málaga, 2021, pp. 201-212, ISSN: 0211-8483, e-ISSN: 2695415X, DOI: http://dx.doi.org/10.24310/BoLArte.2021.vi42.7978 


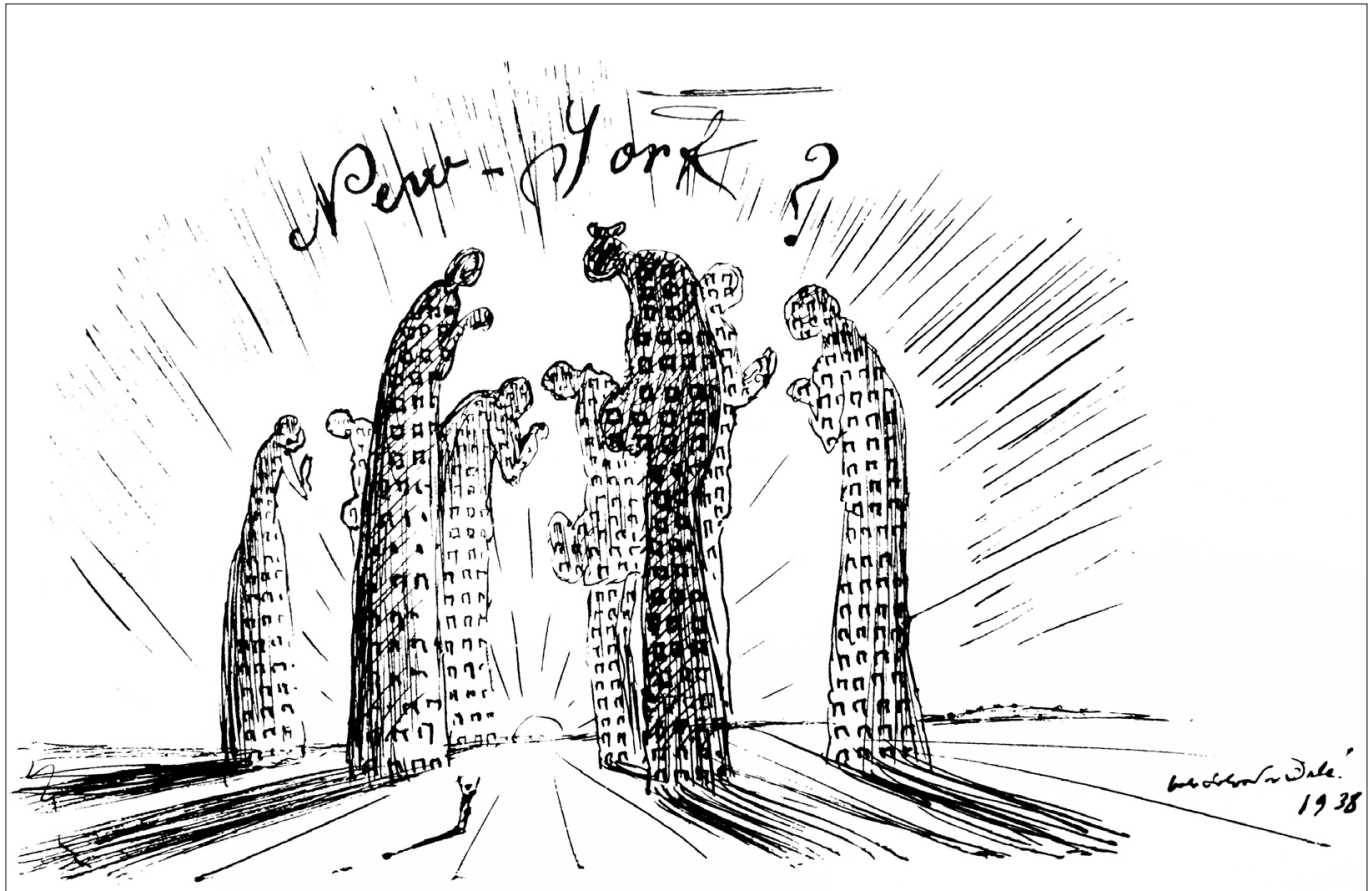

1. Gigantescos ángelus de Millet en Nueva York. Salvador Dalí. 1938
En el libro de El mito trágico de «El ángelus» de Millet se describe el fenómeno delirante inicial como el instante en que aparece por primera vez, de forma violenta, la imagen obsesiva ${ }^{2}$, inicialmente de forma inconsciente, sobre la que se podrá aplicar el método paranoico crítico ${ }^{3}$. Esta imagen ya en su inicio viene acompañada de una idea enigmática y turbadora a la que se le incorpora credibilidad con los fenómenos delirantes secundarios ${ }^{4}$.

En este artículo relacionamos el estadio delirante inicial con el acontecimiento del incendio del edificio TVCC en Beijing del arquitecto Rem Koolhaas, desde que se manifiesta el mismo la imagen real queda anclada al fenómeno delirante de forma instantánea.

En la dimensión paranoico-crítica del cuadro El ángeIus ${ }^{5}$ la arquitectura está en los campesinos, y en la carretilla que provoca el delirio. El resto es anodino, es una envoltura espacial que relata el paisaje deslocalizado para centrar el foco en la esencia. Las distancias intermedias están abandonadas, solo la profundidad del paisaje se muestra como enfatización del acontecimiento. El paisaje es inalcanzable, a través de la huella del suelo que pisan los campesinos el secreto desvela la realidad. No existe por tanto nada más que el sentimiento de muerte frente al ataque sexual inminente.
Los elementos que componen la escena no se suceden en una progresión continua, sino que hay plegamientos temporales de forma geométrica que lo transportan de un espacio a otro girando de forma concéntrica bajo la figura de los pies de los campesinos, desde donde el acontecimiento comienza a emerger. La figura femenina tiene excesiva fuerza en la percepción del conjunto, llegando a invisibilizar el resto y perturbar poniendo en crisis la percepción del conjunto. Su actitud expectante muestra el inicio de la devoración y aniquilación, acto que desencadenará la muerte y la destrucción. La figura masculina se inclina hacia delante en posición sumisa, a la expectativa del acontecimiento, pero preparado, escondiendo una creciente erección bajo el sombrero que sujeta con firmeza. La personalidad erótica de la carretilla en Dalí (1963: 137) revela en su más alto grado la animalidad y atavismo del acontecimiento. Junto con la horca clavada en la tierra arada simboliza el esfuerzo desmesurado del acto sexual [2].

En el análisis que nos realiza Dalí de El ángelus, la inmovilidad y expectación de la campesina es -como en el caso de la mujer que reza en la postura de la mantis- ese momento previo a un ataque y la agresión impasible. Se prepara para la gran prueba de entregar su vida, sintiéndose capaz de sellar su abrazo y ansiado beso con la fuerza de 


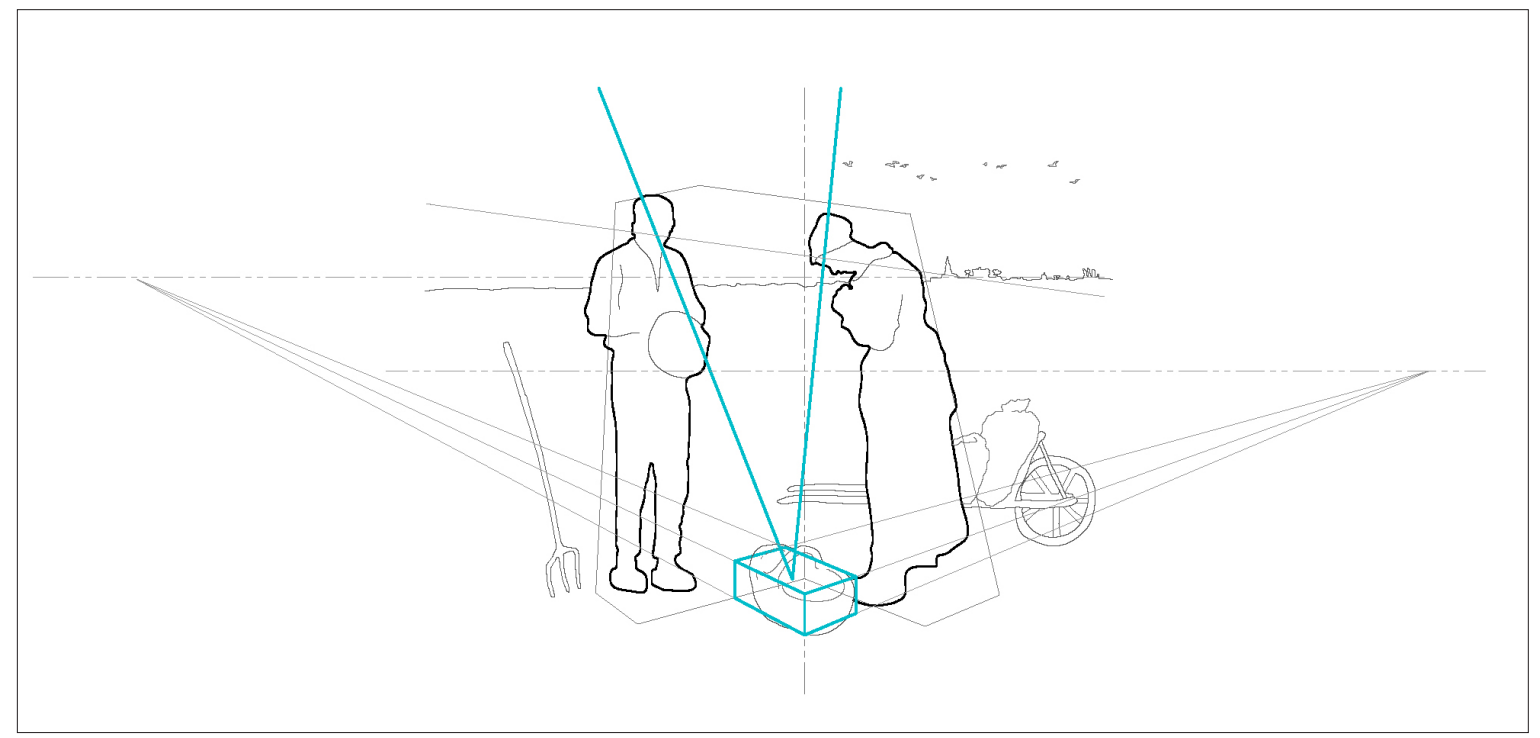

2. Relaciones en el cuadro de El ángelus de Millet. Aparición del ataúd del hijo. Elaboración propia

sus garras que lo atraparían para siempre entre sus brazos, y de este modo con la muerte de uno de los dos. Como Dalí nos relata en la novela Rostros ocultos (1952: 84); terminar su pacto de conformidad con las grandiosas reglas y leyes de la naturaleza de su amor.

Para Dalí (1963: 152), el personaje masculino lo veía bajo un aspecto trastornador, angustioso, como un muerto de una forma latente, como muerto de antemano. Tras los dos campesinos del cuadro, sin duda se nos desvela la geometrización espacial de la silueta del perfil arquitectónico del edificio del CCTV de Rem Koolhaas en Beijing. La mantis religiosa finalmente no ha devorado a su amado tras la finalización del acto sexual, sino que se ha unido a él para siempre con el lazo arquitectónico relacional. Una petrificación del acontecimiento que tendrá que huir de este territorio hostil. El inicio de la vida surge de la pérdida. La muerte es el estado extremo de la vida (Bataille, 1957: 245).

\section{Incendio del TVCC}

El lunes 9 de febrero de 2009, se producía el incendio en el edificio del centro cultural de la CCTV -el TVCC- diseñado por Rem Koolhaas y Ole Scheeren. Edificio que forma parte del complejo de la televisión China en Beijing. Un incendio que le llevó a su total aniquilación y destrucción inmediata. Posteriormente el edificio se reconstruirá, quedando totalmente finalizado en 2012.

Un conjunto de desplazamientos, analogías y relaciones se desatan con la aparición de dos cuadros fundamentales bajo la imagen de los edificios del CCTV, y dos textos asociados a los mismos. Por un lado, el cuadro de El ángelus de Millet, y, por otro, al cuadro de Flagrant Delit de Madelon Vriesendorp.

Los fenómenos, empiezan con el cuadro de El ángelus, la obra más conocida de Jean François Millet. Un cuadro de carácter enormemente piadoso, donde se muestran dos campesinos rezando tras una larga jornada de trabajo en el campo. Pero ahora aparece cargado con toda la simbología y personalidad de la que Dalí le dotó en su libro El mito trágico de «El ángelus» de Millet, apoyando toda esa intencionalidad latente que se encuentra en el mismo, donde la pareja de campesinos presentaba un erotismo implícito, y que aquí trasladamos y relacionamos con el cuadro de Flagrant Delit y el texto de Koolhaas (1978) Delirio de Nueva York, un manifiesto retroactivo para Manhattan, y a los edificios que pueblan nuestras ciudades. Koolhaas manifiesta que lo primero que hizo tras acabar la carrera fue escribir un libro, eso me hizo entender y dar forma a lo que yo quería hacer (Eisenman y Koolhaas, 2007: 97). 


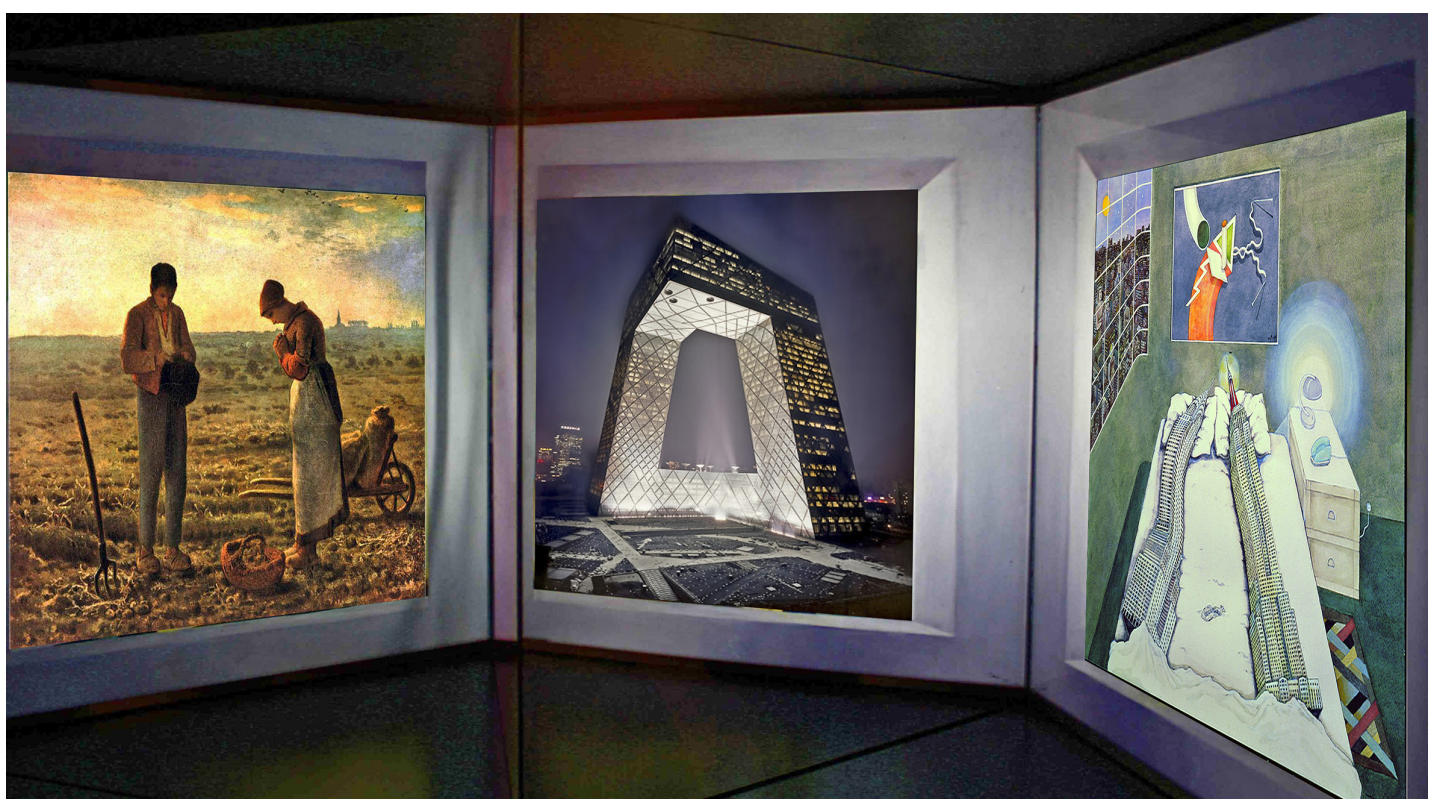

3. Estereoscopio de Dalí. Reconstrucción de la nueva creación entre El ángelus y la pareja del Chrysler y el Empiere State. Elaboración propia

\section{Parejas antagónicas}

En 1975, Madelon Vriesendorp ${ }^{6}$ (2008) dibujaba una serie de pinturas, que se iniciaban con Aprés l'amour, donde dos emblemáticos edificios como el Chrysler y el Empire State mantenían una romántica conversación tras el cortejo que habían consumado a lo largo de la noche en un hotel de la ciudad de Nueva York. En otra de las obras de Madelon Flagrant Delit ${ }^{7}$ esa conversación era observada por un Manhattan expectante, y en su primera versión se les unía una Estatua de la Libertad con cuerpo de Venus de Milo. En medio de la conversación hace entrada en la habitación el Rockefeller Center, y los sorprende tras haber consumado el acto, con la prueba del delito flagrante en el preservativo patrocinado por Goodyear recostado sobre el borde de la cama. En este momento, se produce entre los tres una tensa y densa conversación que igualmente es presenciada por un Manhattan atónito frente al histórico acontecimiento que se estaba produciendo. El éxtasis y el desastre se convierten a la vez en el motor de la escenå .

A finales de los años setenta Dalí trabajaba con estructuras estereoscópicas para desvelar contenidos ocultos en El ángelus. En su texto cuenta una anécdota cuando volvía de la playa tras jugar con varios guijarros y piedras simulando a los campesinos del cuadro, tiene que cruzar a diario un amplio prado, donde en esta ocasión con El ángelus revoloteando aún en su cabeza, tropieza con un pescador. Aunque ya lo había divisado en la lejanía, una vez que lo tiene delante se produce la colisión entre ellos. Ambos realizan los dos típicos gestos idénticos intentando evitar el contacto, como si fueran una misma persona ante el espejo. Un mimetismo que siempre acaba uniendo simétricamente el movimiento de los dos cuerpos sin posibilidad de evitarlo, están predestinados a cruzar sus caminos [3].

Con el estereoscopio Dalí buscaba trabajar esta obsesión por la imagen doble que se prolongaría a lo largo de toda su vida. Mirando con ambos ojos a través del estereoscopio, se ven dos imágenes de un mismo objeto, pero al superponerlas se producen variaciones tridimensionales que reformulan la realidad. Nunca llegó a finalizar el cuadro El ojo de El ángelus. En su estudio de Cadaqués siempre tuvo, y aún se conservan dos cuadros de El ángelus presidiendo su zona de trabajo. Unos elementos inspiradores para toda su obra.

Cada cuadro tiene su pareja antagónica, es bastante evidente que usando el estereoscopio podríamos compren- 
4. Flagrant Delit II. 1975. Madelon Vriesendorp. Imagen de la cubierta original del libro Delirious New York

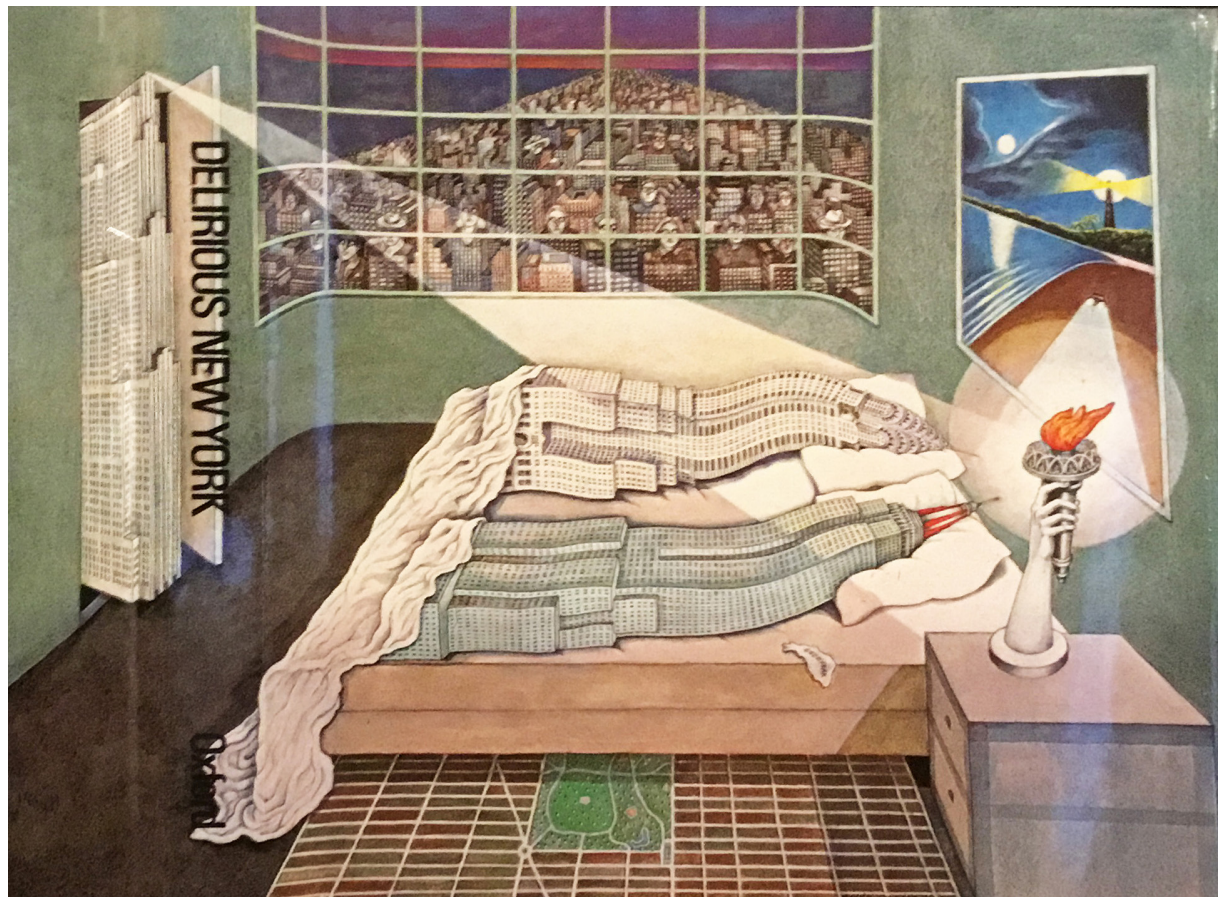

der la relación entre el cuadro El ángelus de Millet interpretado por Dalí y el cuadro de Madelon Vriesendorp Flagrant Delit, mostrándonos al nuevo vástago encarnado en el CCTV. Algo nuevo que brota de la historia, del conocimiento de la cultura arquitectónica, donde la destrucción es fuente de vida [4].

\section{Vida y destrucción}

En 1978, Dalí descubre los trabajos de René Thom y la teoría de las catástrofes (Thom, 1977). La teoría de las catástrofes es una ciencia que trata de entender todas las transformaciones que se producen de un modo brusco, imprevisto, dramático. Los sistemas estructuralmente estables son propensos a manifestar discontinuidades. La catástrofe se muestra como una acción de supervivencia de un sistema obligado a salir de su estado normal. Donde hay un salto brusco o catástrofe se dará una discontinuidad en las propiedades del medio, y, por tanto, la creación de una nueva forma, que emerge del medio continuo.

Para desvelar el contenido que Dalí veía latente en el cuadro de Millet, estuvo buscándole geometrías, argumen- taciones matemáticas y explicaciones a su composición. Él ya sabía que el cuadro contenía un ataúd del hijo muerto de los campesinos localizado cerca de los pies de la madre, ya que le habían informado de dicho pentimento. Lo que argumentaría la angustia inexplicable de esas dos figuras solitarias, unidas por el elemento argumental primordial que estaba ausente (Dalí, 1963: 17). Necesitaba demostrarlo y lo único que era capaz de poder aportar algún razonamiento interesante, era la radiografía que consiguió realizara el Louvre al cuadro. Desmenuzar sus tripas es lo que hizo agitar la inventiva y recomponer las ideas.

En el prólogo de El mito trágico, Dalí usa tres imágenes relevantes: el cuadro de El ángelus, la radiografía sobre el cuadro y una ilustración del imaginario cultural estadounidense del siglo XIX. En esa última se puede ver a una madre despersonalizada utilizando a su vaquero marido como carretilla para fertilizar a la tierra-madre nutridora por excelencia con su falo-cactus, a la vez que realiza la excavación para enterrar al hijo fallecido -imagen que usaría Koolhaas de forma repetida en sus conferencias de los años setenta-. (Gargiani, 2008: 52) [5].

Desde este momento la figura de la muerte comienza a emerger y de repente se levanta una niebla que invisibiliza 


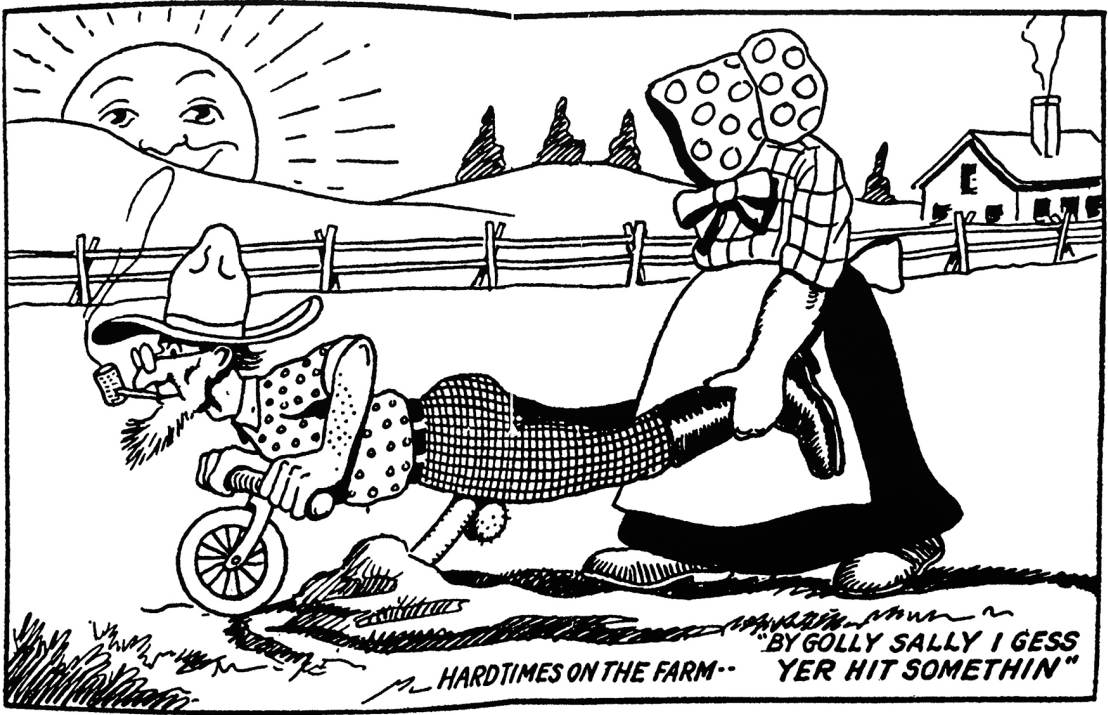

5. llustración folklórica estadounidense del siglo XIX, en El mito trágico de «El ángelus» de Millet. 1963. Salvador Dalí a los dos campesinos. La presencia del ataúd del vástago recientemente fallecido hace tambalear la relación amorosa, pero a la vez renacer el espíritu de la sexualidad. La muerte del hijo se coloca en primer plano. Lo latente se desvela con carácter infinito y con raíces firmes. La muerte posibilita el nacimiento con una nueva creatividad, la destrucción permite la construcción, el fin alumbra el comienzo, la penumbra desaparece y la luz brilla. Es el principio narrativo de la historia que completa el vacío que envuelve a la arquitectura. Ahora todo gira en espiral, de abajo hacia arriba, volviendo sobre los distintos elementos para reconfigurar la imagen sobre sí misma. El torbellino de la vida reformula las estructuras conocidas, ya nada es lo mismo. Las relaciones amorosas de los personajes se han convertido en un triángulo de estructura cambiante.

La película de Buñuel y Dalí Un perro andaluz ${ }^{9}$ finaliza con un plano fijo inquietante al que le precede una última frase «En primavera». La película se rodó en 1929, época en la que Dalí estaba completamente obsesionado con El ángelus, así que decide dejar su sello colocando una interpretación de dicho cuadro marcando igualmente las futuras obras de Buñuel, que utilizaría de nuevo este recurso en otras películas. En este caso El ángelus aparece absolutamente distorsionado y modificado, mostrándose las figuras de los campesinos absorbidas por el territorio. Aparecen semienterradas hasta el pecho de ambos buscando su inmovilidad para no desatar acontecimientos. O siendo más coherentes aparecen agotados tras el acto sexual, además de cambiados de posición. El acontecimiento ya ha sucedido y ha causado tales estragos que el desvanecimiento de ambos se apodera de sus cuerpos terrenales. La mujer aparece con la cabeza inclinada hacia un lado y ahora es el hombre quien se muestra con la cabeza en posición reclinada. La posición de oración ha sido sustituida por la del éxtasis postcoital. El fenómeno del éxtasis se apodera de su cuerpo. Los brazos de ambos están inmovilizados. Es un primer acercamiento a la reformulación del cuadro que empezará a poblar la obra de Dalí [6]

Ahora no es el campo labrado el que pisan los campesinos, sino que la presumible arena de la playa los engulle por el desfallecimiento de sus apoderados cuerpos. El erotismo y la destrucción se manifiestan como actos que se habían desencadenado en la interpretación del original de Millet. Sus ojos se llenan de insectos y la muerte aparece como final a una intensa relación.

El alma queda contenida en la arquitectura. Los campesinos flotan sobre un terreno fértil. La muerte impregna un territorio que se extiende hasta el infinito donde sobre la línea de horizonte la torre se vislumbra como el reflejo del contenido arquitectónico latente en las figuras. Así, el guiño al CCTV aparece manifestado no solo por la agresión inminente de la pareja, sino por la manifestación fálica del elemento arquitectónico frente a la erección que esconde la figura masculina bajo el sombrero. El campanario elimina el suelo y nos 
6. Escena final de Un perro andaluz. Luis Buñuel y Salvador Dalí. 1929

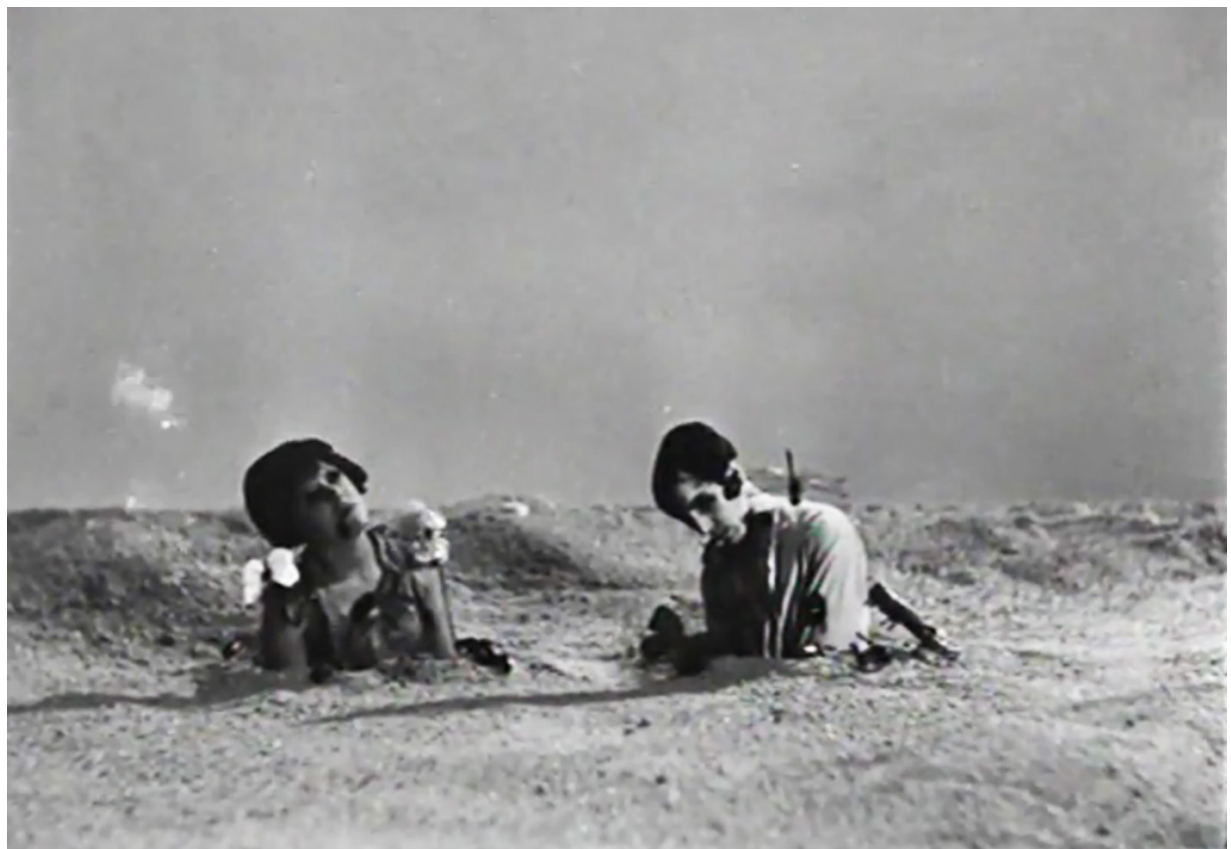

dirige la mirada hacia arriba, evitando que la muerte del hijo cobre demasiada presencia en la apreciación de la escena. Se niega la vinculación a un territorio concreto, cualquier vestigio patrimonial que asiente raíces en este espacio parece ridiculizado. La huida a China es viable. Nueva York no es más que un cúmulo de acontecimientos pasajeros cuya caducidad está anunciada desde el diseño y la construcción en búsqueda de la abundancia y la fertilidad. El suelo es una línea ligeramente horizontal que resguarda la crudeza de la realidad, las miserias del ser, las lágrimas del pasado -véase el cuadro Freud Unlimited de Madelon Vriesendorp-. Entre el cielo y las tripas, se alzan danzando la esbeltez de la radicalidad humana por la conquista de la altura. La feminidad es energía en acción incontrolable, lo masculino aguarda paciente su momento. Entornan sus brazos, inclinan sus cabezas y comienzan un ritual para el alejamiento disimulado de la tierra madre. Un deslizamiento constante y ordenado de confianza en un porvenir plagado de celebraciones y destrucciones. Una senda de esperanza que ilumina el camino. Es el inicio de la manifestación de la muerte en la lucha por la altura. Alguien se ha quedado, pero su momento avanza a la par, sabiendo que al final del camino, en ese punto exacto donde confluye la celebración y la destrucción, se desencontrarán.

\section{Metamorfosis de los edificios}

Los edificios no están solos. Siempre viven acompañados. Las relaciones que se establecen entre ambos se comunican de forma rizomática entre unos y otros si han sido concebidos de forma relacional. El orden de lectura y su estructura es alterado a modo que los miramos de forma distinta a la que siempre nos han obligado a mirar.

Las cualidades de cada edificio, de cada arquitecto, de cada obra están impregnadas de cada uno de nosotros. Su estado de ánimo, su belleza, su carácter, su rigidez, un conjunto de definiciones que hacen que cada uno sea especial. Un compendio de circunstancias incontrolables -o controlables solo por el arquitecto manipulador- que permiten que cada uno aprecie el presente de forma particular dependiendo del momento emocional que está viviendo. Lo sensorial por tanto se convierte en fundamento de derecho para la percepción de la arquitectura. Y desde el punto de vista contrario sucede exactamente lo mismo. La obra, se convierte en arte desde el momento que colabora con su interlocutor, la arquitectura sin el habitante no puede disfrutar de esa experiencia sensorial. Cuanto más conocemos la obra más vida cobra, cuanto más interaccionamos con ella la condición corpórea se fusiona con la pétrea. 


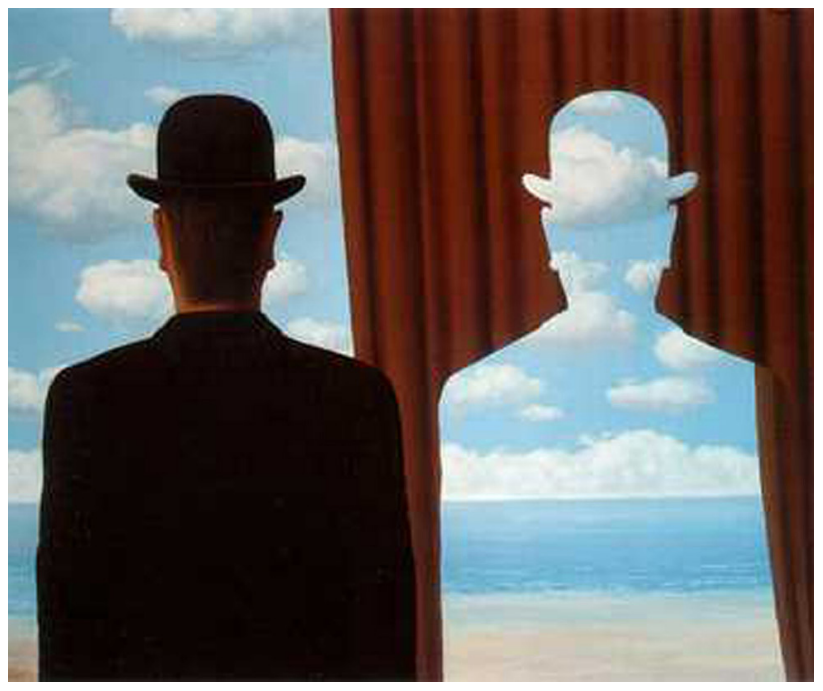

7. Decalcomanía, 1966, René Magritte

Así, una obra es leída a través de su experiencia con el espacio que la rodea y las relaciones que se establecen entre la obra, el entorno y quien se interrelaciona. Una sucesión de experiencias sensoriales y sensitivas, son las que provocan la encarnación de los edificios. Experiencias distintas dan forma a la capacidad de interpretación de la arquitectura. Una secuencia de estímulos continuados debe inundarnos para despertar el interés por percibir lo latente.

$Y$ finalmente hay estructuras formales asociadas que es inevitable enlazar para deformar el entorno y trasmutar la realidad.

Cuando percibimos una obra por primera vez tenemos una impresión inicial que solo se podrá desmontar a través del conocimiento de acontecimientos colaterales. Estos pueden provocar sensaciones de ansiedad, de terror, de agobio; o lo más habitual, pueden generarnos indiferencia, desinterés; o por el contrario pueden despertarnos fascinación, satisfacción, ilusión. Este desencadenamiento emocional junto con la aplicación del método paranoico-crítico es lo que nos permite intercambiar las impresiones y a través del conocimiento dotarle de la nueva identidad para que puedan danzar en la cartografía de ese nuevo mundo. Conseguimos por tanto una Arquitectura con una nueva personalidad marcada por su historia y por el carácter que le aplicamos desde cada uno.

Por tanto, no estamos hablando de una mirada concreta, sino de una acción personal que desencadena la in- terpretación delirante particular. El conjunto de todas ellas, si las hubiera, conformaría esa nueva cartografía del cortejo comunitario.

Un edificio hace prisionero al otro. El uno sin el otro no tienen capacidad de existencia. En El ángelus todos los elementos convivían y los campesinos eran libres. El Empire State, la Chrysler y el Rockefeller Center son independientes de relacionarse con lo que en cada momento convenga. Aquí el sello del amor impide la independencia. Es sensato pensar que la fragilidad de la pareja se convierte en estructura que imposibilita la huida. La búsqueda de la levedad en altura parecía imposible y ahora aprisiona al ser. La levedad es metáfora infinitesimal, escenificación contemporánea del rascacielos. Es una arquitectura que busca la negación de la altura, ya no importa la lucha por la altura, estamos en el momento del establecimiento de relaciones.

El edificio es un mito. La distorsión de la realidad nos hace olvidar que es un cambio de paradigma. Las dos caras del espejo deforman el contorno, la ironía se manifiesta. Para quién lo habita es uno más, para quien lo diseñó el gran logro, para quién interpreta es el reflejo de una vida. Tener un espejo donde mirarse es difícil de mantener cuando los remordimientos son constantes.

Para Lacan (1966: 100), en El estadio del espejo (1949), se produce la transformación en el sujeto cuando asume su imagen doble al verse en el espejo por primera vez de forma conjunta, se abandona la imagen de la fragmentación del cuerpo ${ }^{10}$. El Yo es el resultado de identificarse con la propia imagen doble, el espectro, el reflejo del propio cuerpo en el espejo. Aparece el otro, es uno mismo a la vez que el otro, una alineación de sí mismo, una reproducción virtual del Yo. El edificio y el otro se encontrarán frente al espejo de forma continuada, viviendo en una perpetua irrealidad que les remite a la figura materna, al enlace umbilical. La reproducción la asumen como propia. El Yo está alienado, su estructura es paranoica, confundiendo a la realidad con la ficción. Siendo la alienación constitutiva del orden imaginario, la unión del Yo con el otro rompe el espejo y se presenta como edificio doble. Uno es parte de otro, y la figura de representación virtual en el espejo desaparece.

En Decalcomanía, de René Magritte, podemos observar claramente la figura del doble y que se esconde detrás de ello, se cambia la relación entre los elementos y su representación, lo que produce inquietud y confusión al trans- 
gredir las reglas reales del espacio. Todo elemento deja una huella en el espacio y en cada objeto con el que tiene contacto. Hay una relación entre la ausencia y la presencia, que se mantiene a lo largo de la vida de los objetos. Esto se ve muy claramente en Una pareja con la cabeza llena de nubes de Dalí, donde los campesinos de Millet se han enmarcado con un marco dorado, figuras independientes pero que son inseparables. Ambas siluetas inclinan sus cabezas encontrando su ángulo perfecto para encajar un cuerpo en su homólogo. Están separadas pero íntimamente ligadas formalmente y conceptualmente. Su contenido los reafirma relacionándolos para configurar un único elemento compositivo [7].

La arquitectura es gestadora de espacio, une fragmentos y crea separaciones y conexiones entre exterior $e$ interior. Los edificios se devoran unos a otros. Se roban calor entre ellos. Para Fernández Mallo, robar calor es el primer y más sagrado principio de destrucción ${ }^{11}$.

En el cuadro de Madelon Vriesendorp, Sueño de Libertad, la Estatua de la Libertad penetra dentro de la Chrysler fecundándola. O quizá emerge de la misma tras una fecundación anterior. En una clara alusión a la obra de Dalí, la estatua se dibuja humanizada y con una corporeidad pétrea, se usa la misma técnica que Dalí utilizaba para dibujar sus figuras antropomórficas. El ejemplo más claro es el cuadro Reminiscencia arqueológica de El ángelus de Millet, donde la pareja de campesinos aparece petrificada y convertida en una ruina arquitectónica.

En el cuadro La importancia de las maravillas de René Magritte, se muestra como cada elemento o cuerpo se añade a un mismo cuerpo con nuevas propiedades, después de haber sufrido un acontecimiento. Se roban calor unos a otros, renaciendo sobre sí mismo con nuevos aires. El nuevo cuerpo emerge de la base anterior liberándose de ella. Un elemento que a su vez sustenta antiguos contenedores, cada sección de ellos es una capa de reencarnación de la nueva estructura objetual. Cada nueva reencarnación controla de alguna forma a su anterior existencia, el efecto y la influencia de un objeto sobre otro, de un edificio sobre otro, de su arquitecto en el edificio, y de la gente que lo habita.

La metamorfosis del cuerpo en objeto es el deseo que produce el sueño en su estado de excitación más acusado. En Dalí se podía ver claramente su antropomorfización, y en las imágenes surrealistas de Grandville de 1884 publicadas

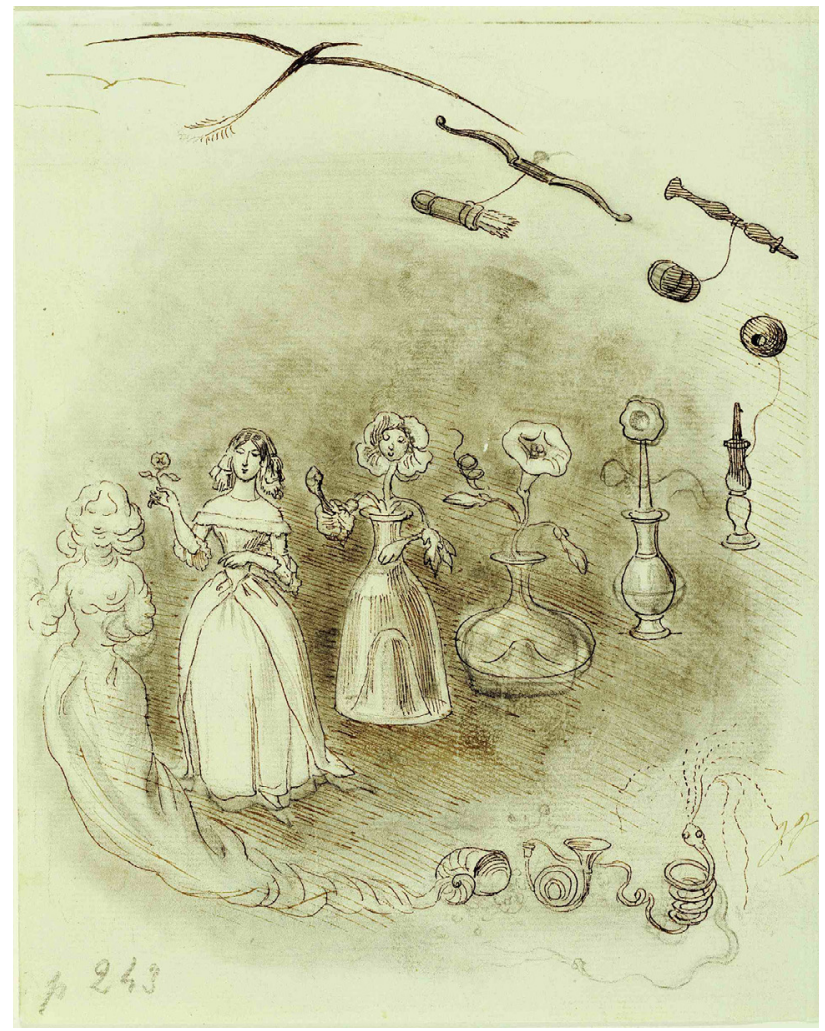

8. La metamorfosis del sueño. J.J. Grandville, 1844. Galerie Ronny Van de Velde, Amberes, Bélgica

en su libro Un mundo distinto ${ }^{12}$, como la Metamorfosis del sueño, podemos ver la conversión en objetos cotidianos que despertarían el interés del Surrealismo para la explotación de los Objetos de funcionamiento simbólico [8].

\section{Conclusiones}

El método paranoico-crítico hace estallar la geometría euclidiana, hace delirar las formas del tiempo y del espacio hasta suspender al espectador, suspenderlo en su expectación.

Dalí realiza una interpretación de El ángelus que le permite desarrollar asociaciones delirantes secundarias que giran alrededor de un centro argumental básico. Así vemos que el procedimiento paranoico es un mecanismo asociativo a partir del cual produce múltiples metáforas explícitas montadas sobre la carcasa de estructuras duras. La paranoia convierte al sujeto en el comunicador de un mensaje que le 


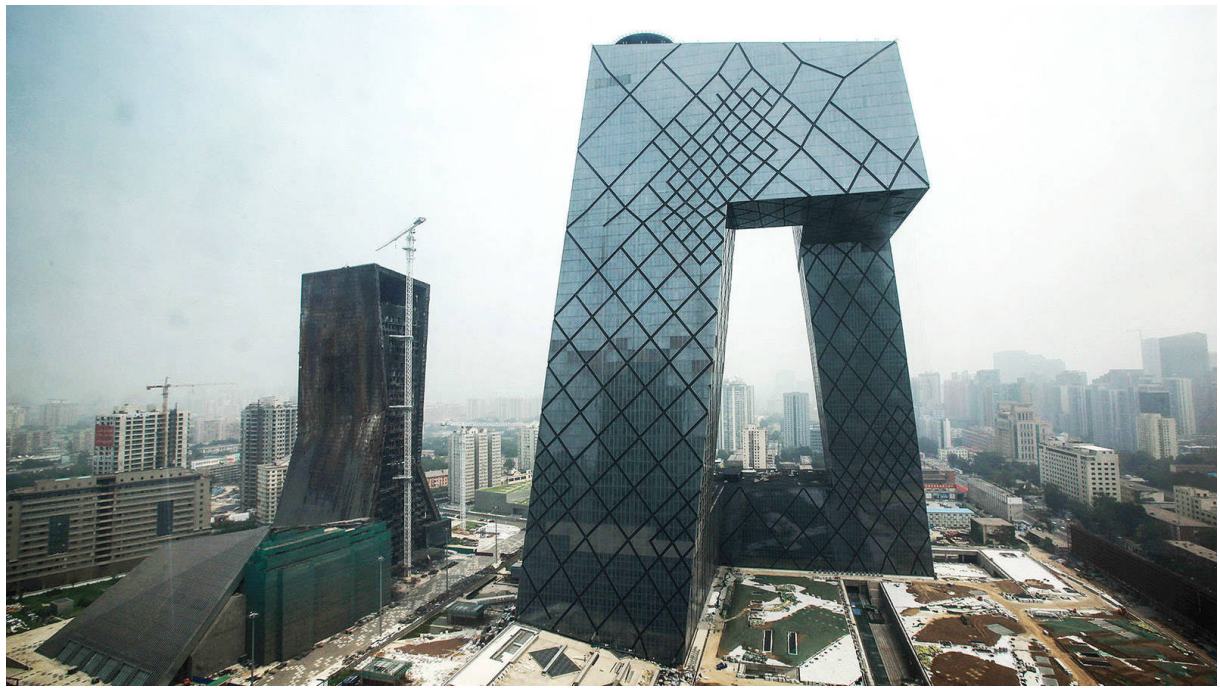

9. Gigantescos ángelus de Millet en Beijing, China. Elaboración propia ha sido revelado, que lo convierte en el místico loco al que nadie escucha.

El CCTV podríamos mostrarlo retratado como una mantis religiosa hembra que sin embargo se estaba preparando para ser la victima aniquilada al fundirse con su amado, variando voluntariamente el sujeto sacrificado en la unión de la pareja como culminación de su amor.

Dalí insistía en que la autoaniquilación es uno de nuestros más violentos y tumultuosos deseos. La naturaleza mezcla la vida con la muerte en lo genital, el caso extremo es cuando la actividad sexual acarrea la muerte del animal

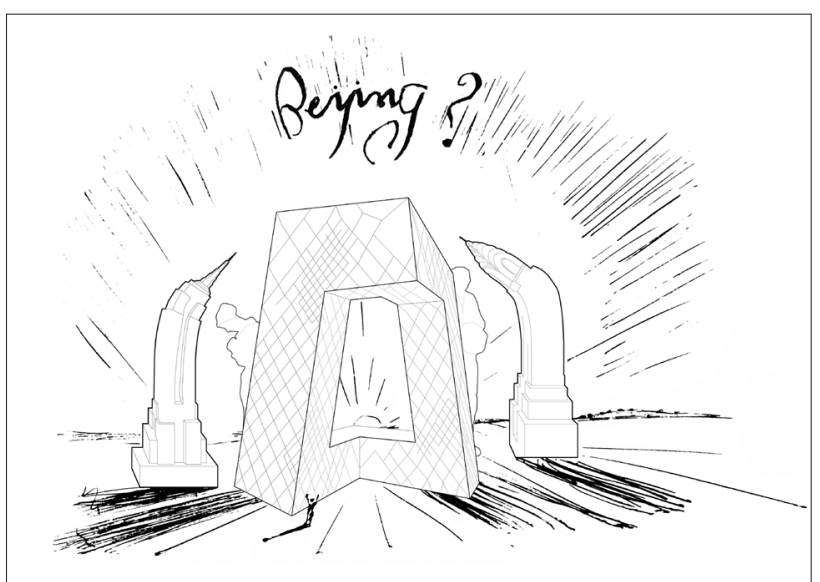

10. CCTV y TVCC en Beijing. Rem Koolhaas. OMA. 2012 que engendra. La que gana al final es la pérdida. La reproducción no multiplica la vida más que en vano, la multiplica para ofrecerla a la muerte (Bataille, 1957: 237).

La destrucción que anunciaba Koolhaas en la ciudad del globo cautivo en 1972 (Ulrich, 2006: 508) se hace real en 2009 en el incendio de uno de los edificios del complejo del CCTV, el TVCC. EI TVCC se convierte en un sujeto postraumático, para Žižek (2014: 90) es una víctima que sobrevive a la muerte de su identidad simbólica, de la destrucción surgirá un nuevo ser renovado. La enunciación de la catástrofe ya apareció anteriormente en 2001 con la caída de las Torres gemelas (Barba, 2014). Aquel(los) edificio(s) al que Koolhaas no le prestaba atención directamente, pero sí que lo miraba de reojo continuamente y le servían de referencia. Ahora le atacan directamente a su persona. Es la obra de arte total. Koolhaas ha conseguido traducir Delirious New York en arquitectura en todas sus facetas, no solo la construcción, sino la propia destrucción. Aquello por lo que tanto ha luchado, ahora se hizo realidad. La destrucción del edificio no es más que la reafirmación de la figura del arquitecto [9] y [10].

Como Gala le dijo a Dalí tras la visita al Louvre para ver la radiografía y comprobar que detrás del cuadro de Millet existía la mancha del ataúd del hijo de los campesinos:

Si ese resultado constituyera una prueba, sería maravilloso; pero si todo el libro no fuera más que una pura construcción del espíritu, jentonces sería sublime! (Dalí, 1963: 20). 


\section{Notas}

1 Libro escrito por Salvador Dalí entre 1932 y 1935. El manuscrito desapareció en 1941 cuando abandonó la ciudad francesa de Arcachon. En 1963 fue reencontrado y publicado por Jean-Jaques Pauvert en Francia. En el libro se describe: el funcionamiento del Método paranoico-crítico inventado por Dalí; el análisis de mito (trágico) de la muerte del hijo y de la mujer castradora en el arte; la hipótesis de que Millet era un gran dibujante de carga erótica.

2 Es la imagen que se aparece de forma inconsciente y obsesiva en el paranoico tras apreciar un acontecimiento violento, que irrumpe dotando de una nueva vida. La imagen puede ser cualquier elemento: un cuadro, un acontecimiento, una idea, un objeto. La importancia radica en el carácter enigmático que tiene la misma y que sirve para desvelar el contenido latente en la realidad adormecida.

3 Desarrollado por Dalí en su libro El mito trágico de «El ángelus» de Millet, donde reconoce la actividad paranoica del pensamiento. Es un proceso de pensamiento activo donde se generan simulacros a partir de imágenes producidas en el subconsciente, que tienen la capacidad de transformar la realidad psíquica. Son imágenes que están conectadas a la imagen real de un objeto. Una vez producida la asociación en primera instancia, esta se repite de forma obsesiva. Se crea así la imagen doble, imágenes que tienen doble significado, para la misma forma desarrollan dos vidas distintas. Esta actividad que introduce el paranoico tiene la capacidad de cambiar la percepción de los otros.

4 Estos fenómenos consisten en la reaparición continuada de la imagen obsesiva en distintos objetos, acciones, edificios o ideas. Distintos acontecimientos de la vida urbana que están impregnados de esta imagen obsesiva que irá desvelándose a modo que la ponemos en carga y se vincula con el fenómeno delirante inicial. No es una actividad automática, sino que es provocada por la acción crítica sobre ellos mismos.

5 Cuadro del pintor realista Jean Francois Millet pintado entre 1857 y 1859 . Es el cuadro principal objeto de análisis por Dalí en su mito trágico, y cuadro fundamental para desencadenar el fenómeno delirante inicial en esta investigación. En el cuadro aparecen dos campesinos a la hora del crepúsculo dando gracias al ángelus por la recolecta de alimento diario. Ya estudiaremos como Dalí le dotó de nuevas connotaciones sexuales y no sería un cuadro tan bucólico.

6 Madelon Vriesendorp fue la esposa de Rem Koolhaas hasta los años 1990 y fundadora de la oficina de arquitectura metropolitana OMA, junto a Rem Koolhaas, Elia y Zoe Zenghelis.

7 Se trata de un dibujo realizado por Madelon Vriesendorp en 1975, donde aparecen representados en la cama de una habitación de hotel, los dos edificios más simbólicos de Nueva York; el Empire State y el Chrysler descansan sobre la cama tras una intensa noche de sexo. Tras la puerta medio abierta aparece un tercer edificio que representa la modernidad, el Rockefeller Center. Es la imagen que acabó ilustrando la portada del libro Delirious New York de Rem Koolhaas en 1978.

8 Véase vídeo Flagrant Delit (1981) en You Tube o la reproducción del StoryBoard de la película «Flagrant Delit» en el libro de las autoras: Vriesendorp y Damisch, 2008.

9 Un perro andaluz. Francia 1929. 22 minutos. Dirigida por Luis Buñuel. Guion de Luis Buñuel y Salvador Dalí.

10 En relación a Lacan y el estadio del espejo puede consultarse el capítulo «Dónde comienza a equivocarse Lacan» del libro Esferas / de Peter Sloterdijk. «Pero es preciso, a la vez, que el engaño sea lo que es: una imagen falaz que ha de ser comprendida en tanto que de ella provienen seducciones que ponen en peligro a uno mismo". Sloterdijk, 2003: 479-483.

11 Agustín Fernández Mallo, «Las alucinaciones negativas», publicado el 26/4/2013 en elcultural.es con motivo de la Exposición sobre Dalí: Todas las sugestiones poéticas y todas las posibilidades plásticas, en el Museo Nacional Centro de Arte Reina Sofía.

12 Grandville, 1884.

\section{Bibliografía}

BARBA, Juan José (2014), Invenciones. Nueva York vs Rem Koolhaas, Bernard Tschumi, Piranesi, Universidad de Alcalá, Alcalá de Henares.

BATAILLE, Georges (2009) [1957], El erotismo, Tusquets, Barcelona.

DALÍ, Salvador (1942), The Secret Life of Salvador Dalí, Dial Press, Nueva York.

DALÍ, Salvador (1978) [1963], El mito trágico de «El ángelus» de Millet, Tusquets. Barcelona. Primera edición Le mythe tragique de «L’Angélus» de Millet, por Société Nouvelle des Éditions Jean-Jacques Pauvert.

DALÍ, Salvador (1952), Rostros ocultos, Luis de Caalt Editor, Barcelona.

EISENMAN, Peter y KOOLHAAS, Rem (2007), Architecture Words I. Supercritical. Peter Eisenman \& Rem Koolhaas, Architectural Association, Londres.

FERNÁNDEZ MALLO, Agustín (2013) «Las alucinaciones negativas», publicado el 26/4/2013 en elcultural.es.

GARGIANI, Roberto (2008), Rem Koolhaas / OMA. The Construction of Merveilles, EPFL Press, Lausana.

GRANDVILLE, J.J (1884), Un autre monde: transformations, visions, incarnations ... et autres choses, H. Fournier, París.

KOOLHAAS, Rem (1978), Delirious New York: A retroactive Manifesto for Manhattan, Academy Editions, Londres.

LACAN, Jacques: (1966), «Le stade du miroir comme formeteur de la fonction du je,telle qu'elle nous est révélée dans l'expérience psychanalytique», en Écrits, Seuil, París.

SLOTERDIJK, Peter (2003), Esferas I, Siruela, Madrid. 
(1978), «Surrealism. Double Issue», Architectural Design, vol. 48, n. ${ }^{\circ}$ 2-3, pp. 152-164.

THOM, René (1977), Stabilité structurelle et morphogénèse, Interédition, París.

ULRICH OBRIST, Hans (2006), The conversations series. Rem Koolhaas, Verlag der Buchhandlung Walther König, Colonia.

Un perro andaluz. Francia 1929. 22 minutos. Dirigida por Luis Buñuel. Guion de Luis Buñuel y Salvador Dalí.

VRIESENDORP, Madelon (2008), The world of Madelon Vriesendorp, AA Publications, Londres.

VRIESENDORP, Madelon y DAMISCH, Teri-Wehn (2008), Flagrant Delit: Dream of Liberty, Aedes Gallery, Berlín.

ŽIŽEK, Slavoj (2014), Acontecimiento, Ensayo Sexto Piso, Madrid. 